\title{
Implementation of mercury biomonitoring in German adults using dried blood spot sampling in combination with direct mercury analysis
}

\author{
Ann-Kathrin Schweizer • Michael Kabesch • \\ Caroline Quartucci · Stephan Bose-O'Reilly • \\ Stefan Rakete
}

Received: 3 March 2021 / Accepted: 28 June 2021 / Published online: 10 July 2021

(C) The Author(s) 2021

\begin{abstract}
Venous blood is a preferred matrix for the determination of total mercury $(\mathrm{Hg})$ in human biomonitoring but has some drawbacks such as the requirement for an uninterrupted cold chain for transport and storage and the need of medical personnel for sample collection. Therefore, we tested and implemented a simpler and less expensive method
\end{abstract}

Supplementary information The online version contains supplementary material available at https://doi. org/10.1007/s10661-021-09254-0.

A.-K. Schweizer · M. Kabesch · S. Bose-O'Reilly University Children's Hospital Regensburg (KUNO) At the Hospital St. Hedwig of the Order of St. John and the University Hospital, University of Regensburg, Regensburg, Germany

M. Kabesch · S. Bose-O'Reilly

Member of the Research and Development Campus Regensburg (WECARE), Hospital St. Hedwig of the Order of St. John, Regensburg, Germany

C. Quartucci · S. Bose-O'Reilly · S. Rakete $(\bowtie)$ Institute and Clinic for Occupational, Social and Environmental Medicine, University Hospital, LMU Munich, Ziemssenstraße 1, 80336 Munich, Germany e-mail: stefan.rakete@med.uni-muenchen.de

S. Bose-O'Reilly

Institute of Public Health, Medical Decision Making and Health Technology Assessment, Department of Public Health, Health Services Research and Health Technology Assessment, UMIT (Private University for Health Sciences, Medical Informatics and Technology), Hall in Tirol, Austria for measuring $\mathrm{Hg}$ in human blood using dried blood spots (DBS). For method development, we investigated the influence of different storage conditions (temperature, storage vessel, time) on DBS samples. For method validation, we compared DBS and venous blood and investigated whether DBS sampling is suitable for measuring $\mathrm{Hg}$ in the general population in countries with low $\mathrm{Hg}$ exposure such as Germany. Based on our results, we found that pre-cleaned glass tubes were most suitable for storage of DBS samples, as this allowed the samples to remain stable for at least 4 weeks even at high temperatures $\left(40{ }^{\circ} \mathrm{C}\right)$. When comparing venous blood and DBS, a very good correlation $(\mathrm{r}=0.95, p<0.01$, Spearman-Rho $)$ and high precision of DBS (mean relative standard deviation $8.2 \%$ vs. $7.2 \%$ in venous blood samples) were observed. Comparing the recoveries of both matrices in different concentration ranges, the variation of the recoveries decreases with increasing $\mathrm{Hg}$ concentration. The mean recoveries also decreased with increasing $\mathrm{Hg}$ concentration. Overall, we found comparable results for DBS and venous blood using direct $\mathrm{Hg}$ analysis. Furthermore, we demonstrated that DBS are suitable for $\mathrm{Hg}$ biomonitoring in the general population in Germany and improved the storage conditions for the DBS.

Keywords Mercury · Biomonitoring - Dried blood spots $\cdot$ Microsampling 


\section{Introduction}

Mercury $(\mathrm{Hg})$ is a toxic metal and a hazard for humans and the environment (UNEP, 2013). Even low exposure to $\mathrm{Hg}$ has negative effects on the health of humans, e.g., on cardiovascular, reproductive, renal, and central nervous systems, and, in particular, during pregnancy and infanthood, cognitive development can be disturbed at low levels of exposure (Afrifa et al., 2019; Bose-O'Reilly et al., 2010; Genchi et al., 2017). To be able to study these associations in detail, simple methods to sample $\mathrm{Hg}$ in those populations, e.g., newborns, are needed. $\mathrm{Hg}$ can occur in the elemental, inorganic (e.g., $\mathrm{HgCl}_{2}$ ), or organic form (e.g., methylmercury), with each species having different toxicodynamic properties (Bernhoft, 2012; Bose-O'Reilly et al., 2010). The major anthropogenic sources of $\mathrm{Hg}$ emissions are the burning of fossil fuels and artisanal and smallscale gold mining (ASGM) activities (UNEP, 2019). In ASGM areas, the use of elemental $\mathrm{Hg}$ is a major source of $\mathrm{Hg}$ exposure (Bose-O'Reilly et al., 2017; Nyanza et al., 2019; Sundseth et al., 2017). In highincome countries, the main source of $\mathrm{Hg}$ exposure is the consumption of fish, e.g., tuna, which may contain a high amount of organic $\mathrm{Hg}$ due to the accumulation in the food chain (Bose-O'Reilly et al., 2010; Sundseth et al., 2017).

To assess $\mathrm{Hg}$ exposure in human blood, venous blood sampling represents the current gold standard. Challenges in using venous blood as a sample material include the necessary availability of trained medical personnel and the maintenance of an uninterrupted cooling chain prior to laboratory analysis. This may lead to relatively high logistical efforts and costs. Furthermore, venipuncture is a more invasive technique compared to other methods of specimen collection and is ethically concerning for certain populations such as infants and children (Basu et al., 2017, 2018; Funk et al., 2015; Nyanza et al., 2019; Ostler et al., 2014; Santa-Rios et al., 2020). As an alternative to venous blood sampling, dried blood spot (DBS) sampling can be used for $\mathrm{Hg}$ biomonitoring (Basu et al., 2017; Chaudhuri et al., 2009; Funk et al., 2013, 2015; Nelson et al., 2016; Nyanza et al., 2019; Perkins \& Basu, 2018; Santa-Rios et al., 2020). Here, capillary blood, e.g., from the finger, is collected on special filter cards.
In contrast to venous blood sampling, only a few drops of blood (approximately $60 \mu \mathrm{l}$ per circle) are needed. DBS sampling usually do not require cooling, extensive storage space, or even medically trained personnel, therefore increasing the feasibility of this method for studies of large populations or in remote areas with limited laboratory infrastructure (Basu et al., 2017; Chaudhuri et al., 2009; Lehmann et al., 2013; McDade et al., 2007; Nelson et al., 2016; Ostler et al., 2014; Santa-Rios et al., 2020).

So far, only three studies compared DBS with venous blood sampling for human biomonitoring of Hg (Funk et al., 2015; Nyanza et al., 2019; Santa-Rios et al., 2020). One study found a relationship between venous blood and DBS, but it was confounded by the high background contamination of DBS cards, which is why the authors considered the retrospective use of DBS without pre-cleaning of the cards inappropriate (Funk et al., 2015). A second study showed that the $\mathrm{Hg}$ levels in DBS samples from pregnant women, who live in an ASGM area, were comparable to venous blood levels (Nyanza et al., 2019). Furthermore, it was demonstrated that DBS are comparable to associated venous blood levels with samples from low exposed persons, too, when methylmercury and inorganic mercury were analyzed using gas chromatography-cold vapor atomic fluorescence (GCCVAFS) (Santa-Rios et al., 2020). However, DBS sampling has so far not been used for biomonitoring of total $\mathrm{Hg}$ in blood in the general population in countries with an expected low exposure, e.g., Germany, in combination with direct $\mathrm{Hg}$ analysis. The implementation of DBS sampling for $\mathrm{Hg}$ biomonitoring comes with multiple challenges such as the background contamination of DBS cards as well as potential contamination or loss of $\mathrm{Hg}$ during sampling, transport, and storage (Basu et al., 2017; Chaudhuri et al., 2009; Funk et al., 2013, 2015; Lehmann et al., 2013; Nyanza et al., 2019; Santa-Rios et al., 2020).

Only few studies dealt with the storage stability of $\mathrm{Hg}$ in DBS samples (Chaudhuri et al., 2009; Perkins \& Basu, 2018; Santa-Rios et al., 2020). In these studies, $\mathrm{Hg}$ in DBS samples was found to generally stable under the investigated conditions. However, no studies have been carried out on the influence of different storage vessels for DBS, although its storage is an important factor for possible contamination of DBS samples. 
The aim of this study was the development and validation of a biomonitoring method for total $\mathrm{Hg}$ in capillary blood using DBS sampling in combination with direct $\mathrm{Hg}$ analysis. Therefore, DBS and venous blood samples were collected from German adults to evaluate if both sampling methods will provide comparable results. Additionally, the influence of different storage vessels on the stability of $\mathrm{Hg}$ in DBS samples was investigated.

\section{Material and methods}

Used materials

$\mathrm{Hg}$ ICP standard $(998 \pm 8 \mathrm{mg} / \mathrm{l}$ in $10 \%$ nitric acid), hydrochloric acid (30\%) for trace metal analysis, and nitric acid (65\%) for trace metal analysis were obtained from Merck (Darmstadt, Germany). Whatman ${ }^{\circledR} 903$ protein saver cards for DBS sampling were obtained from Sigma-Aldrich (St. Louis, USA). Disposable lancets (Solofix ${ }^{\circledR}$ ) from B. Braun (Melsungen, Germany) were used for fingerpricks. LDPE plastic zip lock bags $(22 \times 16 \mathrm{~cm})$ for DBS storage were obtained from Buerkle (Bad Bellingen, Germany). Borosilicate glass tubes with plastic screw caps $(98 \times 16 \mathrm{~mm})$ for DBS storage were obtained from Schuett-biotec (Goettingen, Germany). Certified reference materials for blood (ClinChek®, RECIPE, Munich, Germany) from different batches were used for stability experiments (Hg concentration: $2.5 \mu \mathrm{g} / \mathrm{l}$ and $8.4 \mu \mathrm{g} / \mathrm{l}$ ) and quality control during the analysis of the participants' DBS samples (Hg concentration: $2.9 \mu \mathrm{g} / \mathrm{l})$.

\section{Storage stability of $\mathrm{Hg}$ in DBS}

In order to investigate the influence of different storage conditions on $\mathrm{Hg}$ levels in DBS, fresh venous blood from one volunteer was used for the following experiments. In detail, three spots of one DBS card were spiked with $55 \mu \mathrm{l}$ blood in order to be within the circled line and dried for $2 \mathrm{~h}$ at room temperature. To test the influence of the storage vessel, the prepared DBS cards were individually stored in plastic bags, untreated glass tubes, and glass tubes that had been pre-cleaned with an aqueous mixture of hydrochloric and nitric acid (each 5\%, v/v), respectively (Figure $\mathrm{S} 1$ ). In detail, the glass tubes were filled with $5 \mathrm{ml}$ acid mixture and put on a roll mixer for $2 \mathrm{~h}$. Afterwards, the tubes were rinsed twice with ultrapure water and dried at $100{ }^{\circ} \mathrm{C}$ in an oven. In order to store DBS samples in the glass tubes, the DBS spots were cut out approximately $5 \mathrm{~mm}$ below the circled line using an acid-washed stainless steel scissor. To test the influence of the storage temperature, each storage vessel was stored at $-20{ }^{\circ} \mathrm{C}$, room temperature, and $40{ }^{\circ} \mathrm{C}$ for 1,2 , and 4 weeks, respectively. Every single experiment was conducted in duplicate. As a reference, $\mathrm{Hg}$ levels were additionally analyzed in DBS cards prepared in the same way as described above immediately after drying. Furthermore, the stability of $\mathrm{Hg}$ in DBS was also tested using certified reference material for blood $\mathrm{Hg}$ concentration: $2.5 \mu \mathrm{g} / \mathrm{l}$ and $8.4 \mu \mathrm{g} / \mathrm{l}$, storing the prepared DBS cards in plastic bags at $40{ }^{\circ} \mathrm{C}$ for up to 4 weeks.

Application of DBS for human biomonitoring of $\mathrm{Hg}$

\section{Study design}

This proof-of-principle study was conducted at the Institute and Clinic for Occupational, Social and Environmental Medicine, LMU University Hospital Munich. The study was carried out in accordance with the Code of Ethics of the Declaration of Helsinki for experiments involving human subjects and reviewed and approved by the ethics committee of the Ludwig Maximilians University of Munich (20-091). Participants had to be at least 18 years old and no individual restrictions for venous and capillary blood sampling. In total, 53 participants were randomly recruited at the Institute and Clinic of Occupational, Social and Environmental medicine at the LMU University Hospital Munich in June and July 2020. Prior to the sampling, each participant was informed about the study and signed an informed consent form. Each participant was asked to fill out a questionnaire about potential $\mathrm{Hg}$ exposure (e.g., fish consumption and dental amalgam).

\section{Sample collection}

Venous blood samples from all participants were collected into $7 \mathrm{ml}$ Lithium-Heparin-coated tubes for trace metal analyses (Sarstedt ${ }^{\circledR}$ ) and stored at $-20{ }^{\circ} \mathrm{C}$ until analysis. For DBS sampling, the same 
participant was asked to wash his hands thoroughly to prevent contamination during the sampling. Afterwards, one finger was disinfected and pricked with a sterile disposable lancet. The first drop of blood was discarded before filling three spots of one DBS card with capillary blood. If the blood flow stopped before the circled area of three spots was completely filled, another finger was punctured with the consent of the participant. The DBS samples were dried for $2 \mathrm{~h}$ at room temperature. To test the influence of storage on real samples, some DBS samples $(\mathrm{n}=18)$ were analyzed immediately after drying. The remaining samples $(n=32)$ were stored for 1 week at room temperature in a pre-cleaned glass tube as described above.

\section{Sample analysis}

All samples were analyzed by direct $\mathrm{Hg}$ analysis using a DMA80-evo® instrument (MLS Mikrowellen-Labor-Systeme GmbH, Leutkirch, Germany). $\mathrm{Hg}$ was detected by atomic absorption at $253.5 \mathrm{~nm}$. The quantification was based on an external calibration. Before every analysis series, the sample boats were preconditioned to avoid interference by residual $\mathrm{Hg}$. For venous blood, $100 \mu \mathrm{l}$ blood were directly pipetted into the sample boats and analyzed. Each venous blood sample was at least analyzed in triplicate. For DBS, three completely filled circles were punched out using a pre-cleaned 0.5 -inch stainless steel paper puncher. The punched circles, which contained approximately $60 \mu \mathrm{l}$ (specification by the manufacturer, $55 \mu \mathrm{l}$ for stability experiments) blood, were individually placed directly into the sample boat of the instrument and analyzed to yield three individual values per participant. One blank per participant was prepared in the same manner using an empty circle from the same DBS card. The limits of detection (LOD) were $0.02 \mu \mathrm{g} / \mathrm{l}$ for venous blood and $0.14 \mu \mathrm{g} / \mathrm{l}$ for DBS samples, respectively (for detailed information, see Table S1). The limits of quantitation (LOQ) were $0.04 \mu \mathrm{g} / \mathrm{l}$ for venous blood and $0.28 \mu \mathrm{g} / \mathrm{l}$ for DBS samples, respectively. For quality assurance, an aqueous $\mathrm{Hg}$ standard solution $(10 \mu \mathrm{g} / \mathrm{l})$ and certified reference material for blood ( $\mathrm{Hg}$ concentration: $2.9 \mu \mathrm{g} / \mathrm{l})$ were analyzed daily prior to the analysis of the samples. Day-to-day variation of the $\mathrm{Hg}$ standard and certified reference material was less than $10 \%$.
Statistical analysis

For data processing, Excel 2016 was used. Statistical analysis was performed with IBM SPSS $®$ Statistics, Version 25. Samples below the LOD or the LOQ were excluded from the statistical analysis. For evaluation of the accuracy of DBS, the recovery was calculated from the $\mathrm{Hg}$ levels in DBS and venous blood $\left(\mathrm{Hg}_{\mathrm{DBS}} /\right.$ $\left.\mathrm{Hg}_{\mathrm{VB}} * 100 \%\right)$. Differences in recoveries due to the storage conditions were analyzed using single factor ANOVA and post-hoc tests (Sheffé, Bonferoni). For information about the $\mathrm{Hg}$ levels in venous blood and DBS samples of the study population, median, geometric mean, minimum, and maximum were used due to the non-normal distribution of $\mathrm{Hg}$ levels in blood. Correlation between $\mathrm{Hg}$ levels in DBS and venous blood was analyzed by Spearman-Rho test. JonkheereTerpstra tests were performed to evaluate the differences in the recoveries between individual concentration ranges ( $\mathrm{Hg}$ levels in venous blood: $<0.5 \mu \mathrm{g} / \mathrm{l}$, $0.5-1.0 \mu \mathrm{g} / \mathrm{l}, 1.0-1.5 \mu \mathrm{g} / \mathrm{l},>1.5 \mu \mathrm{g} / \mathrm{l})$. Data was graphically displayed using bar charts, scatter plots, and Bland-Altman plot.

\section{Results and discussion}

\section{Storage stability of $\mathrm{Hg}$ in DBS}

To evaluate the effect of different storage conditions, DBS samples were stored in different vessels at different temperatures and for different times. The mean $\mathrm{Hg}$ level in DBS samples when analyzed directly after drying was $0.81 \mu \mathrm{g} / 1$ (100\%). In Fig. 1, the recoveries of $\mathrm{Hg}$ in DBS cards that have been stored under different conditions are shown. For pre-cleaned glass tubes (a), recoveries varied from 78 to $99 \%$ and the differences between the groups were not significant. For plastic bags, recoveries varied between 70 and $240 \%$. For storage at $-20{ }^{\circ} \mathrm{C}$ and room temperature, no significant differences between the groups were found. In contrast, recoveries significantly increased after 2 and 4 weeks of storage when the samples were kept at $40{ }^{\circ} \mathrm{C}(p<0.01)$. $\mathrm{Hg}$ recoveries in the uncleaned glass tubes showed high variability that could not be explained by the storage conditions, although mean recoveries were good for the majority of the tested conditions (Figure S3). 


\section{Effect of storage conditions on the $\mathrm{Hg}$ recovery in DBS cards}
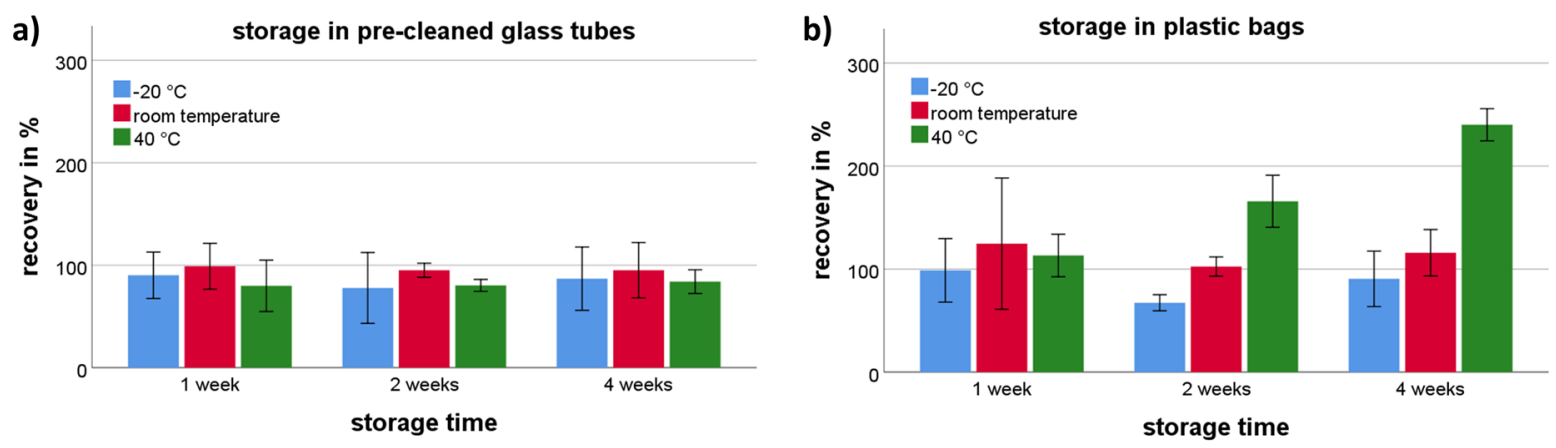

Fig. 1 Effect of storage conditions (temperature, time) on the Hg recovery in DBS cards stored in pre-cleaned glass tubes a) or plastic bags b). Each column shows the mean recovery from six individual DBS spots and the error bars (standard deviation)

Based on these results, we decided to use precleaned glass tubes for the storage of DBS samples in the further course of this study. Consequently, we believe that the samples will be stable for at least 4 weeks, even when stored at $40{ }^{\circ} \mathrm{C}$. Uncleaned glass showed good results, too. However, the results suggest that individual glass tubes may be contaminated with residual amounts of $\mathrm{Hg}$, e.g., during manufacturing, and therefore require cleaning before they can be used as containers for DBS samples. The majority of previously published studies that use DBS samples for $\mathrm{Hg}$ biomonitoring use plastic bags for storage (Chaudhuri et al., 2009; Funk et al., 2015; Nelson et al., 2016; Perkins \& Basu, 2018; Santa-Rios et al., 2020). Although the storage of DBS samples in plastic bags showed satisfying recoveries at $-20{ }^{\circ} \mathrm{C}$ and room temperature in our experiments, $\mathrm{Hg}$ levels were significantly elevated when the samples were stored at $40{ }^{\circ} \mathrm{C}$. The elevated $\mathrm{Hg}$ levels may be explained by residual $\mathrm{Hg}$ in the bags or ambient $\mathrm{Hg}$ that could penetrate the plastic bag and bind to the dried blood. Other studies recommend the use of metal-free plastic bags or cleaning procedures (Funk et al., 2015; Nyanza et al., 2019). However, we preferred glass tubes to plastic bags, as the handling for cleaning and drying of the tubes was relatively simple.

Interestingly, accumulation of $\mathrm{Hg}$ in DBS samples has not been observed when certified reference material for blood, which also has been used in several other studies, was used instead of fresh blood for stability experiments (Figure S4) (Basu et al., 2017; Chaudhuri et al., 2009; Funk et al., 2015;
Nelson et al., 2016; Nyanza et al., 2019; Santa-Rios et al., 2020). As blank values were also not affected by any storage condition (supplementary material), we assume that the accumulation of $\mathrm{Hg}$ during storage only affects DBS samples made from freshly drawn blood. Consequently, freshly drawn blood, e.g., venous blood, should be preferably used for method development.

Correlation of $\mathrm{Hg}$ in venous blood and DBS samples

In total, 53 participants were recruited. One participant was excluded because only one circle on the DBS card was completely filled. Two participants were excluded because of possible sample contamination. In contrast, six participants with only two DBS spots used for $\mathrm{Hg}$ analysis were included in the study. Consequently, the data from 50 participants was used for further analysis. The results for venous blood and DBS samples are shown in Table 1. The Hg levels in one venous blood sample were below the LOD, in another below the LOQ. For DBS, six samples were below the LOQ and therefore excluded from further analysis. Stratification of the $\mathrm{Hg}$ levels in venous blood by gender, age, fish consumption, and dental amalgam fillings can be found in the Supporting Information (Table S2). The individual mean $\mathrm{Hg}$ values in venous blood and DBS samples can be found in the Supporting Information (Table S3).

Regarding the precision of $\mathrm{Hg}$ analysis, venous blood sampling was slightly but not significantly superior to DBS sampling. Although more than 50\% 
Table $1 \mathrm{Hg}$ levels in venous blood and DBS samples of the study participants $(\mathrm{n}=50)$

\begin{tabular}{lllllll}
\hline & $\begin{array}{l}\text { GM } \\
{[\mu \mathrm{g} / \mathrm{l}]}\end{array}$ & $\begin{array}{l}\text { Median } \\
{[\mu \mathrm{g} / \mathrm{l}]}\end{array}$ & $\begin{array}{l}\text { Min } \\
{[\mu \mathrm{g} / \mathrm{l}]}\end{array}$ & $\begin{array}{l}\text { Max } \\
{[\mu \mathrm{g} / \mathrm{l}]}\end{array}$ & $\begin{array}{l}\text { Min }- \text { Mean }- \text { Max RSD* } \\
{[\%]}\end{array}$ & $\begin{array}{l}<20 \% \text { RSD* } \\
n(\%)\end{array}$ \\
\hline Venous blood & 0.65 & 0.87 & <LOD & 4.35 & $0.7-7.2-22.8$ & $45(94)$ \\
DBS & 0.67 & 0.73 & <LOQ & 3.18 & $0.0-8.2-29.8$ & $41(93)$ \\
\hline
\end{tabular}

$G M$, geometric mean; $R S D$, relative standard deviation from three individual analysis; $L O Q$, limit of quantitation; $D B S$, dried blood spots, * samples below the LOD/LOQ were excluded

samples of both venous blood and DBS showed a relative standard deviation (RSD) of less than $10 \%$, mean RSD of venous blood samples was lower compared to DBS (7.2\% vs. $8.2 \%)$. Furthermore, $94 \%$ of the venous blood samples were below an RSD of $20 \%$ compared to $93 \%$ of the DBS samples. This may be explained by residual $\mathrm{Hg}$ in the filter paper. As other studies report, residual $\mathrm{Hg}$ is likely not homogenously distributed in the filter paper, limiting the correction for blank samples from the same DBS card (Funk et al., 2015). Nevertheless, precision of DBS sampling was relatively comparable to venous blood sampling.

The correlation of the $\mathrm{Hg}$ levels in venous blood and DBS samples is shown in Fig. 2. We found a very strong linear correlation between $\mathrm{Hg}$ levels in venous blood and DBS samples $(r=0.95, p<0.001$, Spearman-Rho). This is comparable to what has been found by Nyanza et al. (2019) and Santa-Rios et al. (2020). The majority of the samples were within the desired recovery range between 70 and 130\% (75\%). Overall, recoveries ranged between 62 and $210 \%$. However, recoveries of more than $150 \%$ were only observed for samples with venous blood $\mathrm{Hg}$ levels of less than $0.5 \mu \mathrm{g} / \mathrm{l}$. The associated Bland-Altman plot (Fig. 3) further confirms that DBS sampling and venous blood sampling are comparable methods, although the results for DBS samples were on average $0.09 \mu \mathrm{g} / \mathrm{l}$ lower than what has been found for venous blood samples (bias). Additionally, the recovery of $\mathrm{Hg}$ levels in DBS samples depended on the concentration of $\mathrm{Hg}$ in venous blood. In fact, there was statistically significant negative correlation $(p<0.01)$ between the mean $\mathrm{Hg}$ level of both methods and the difference between the $\mathrm{Hg}$ levels in DBS and venous blood samples.

In Fig. 4, the recoveries of DBS samples stratified by concentration ranges are shown. Median recoveries significantly decreased with increasing $\mathrm{Hg}$ levels in venous blood ( $p=0.001$, Jonkheere-Terpstra test). Additionally, the variation of the recoveries was lowest when the $\mathrm{Hg}$ levels in venous blood were above $1.5 \mu \mathrm{g} / \mathrm{l}$. This may be explained by the fact that residual $\mathrm{Hg}$ on the DBS cards has a higher impact on the
Fig. 2 Correlation of $\mathrm{Hg}$ levels in venous blood and DBS samples $(n=44)$. The straight line represents the identity line; the dashed lines delimit the desired DBS recovery range of 70 to $130 \%$

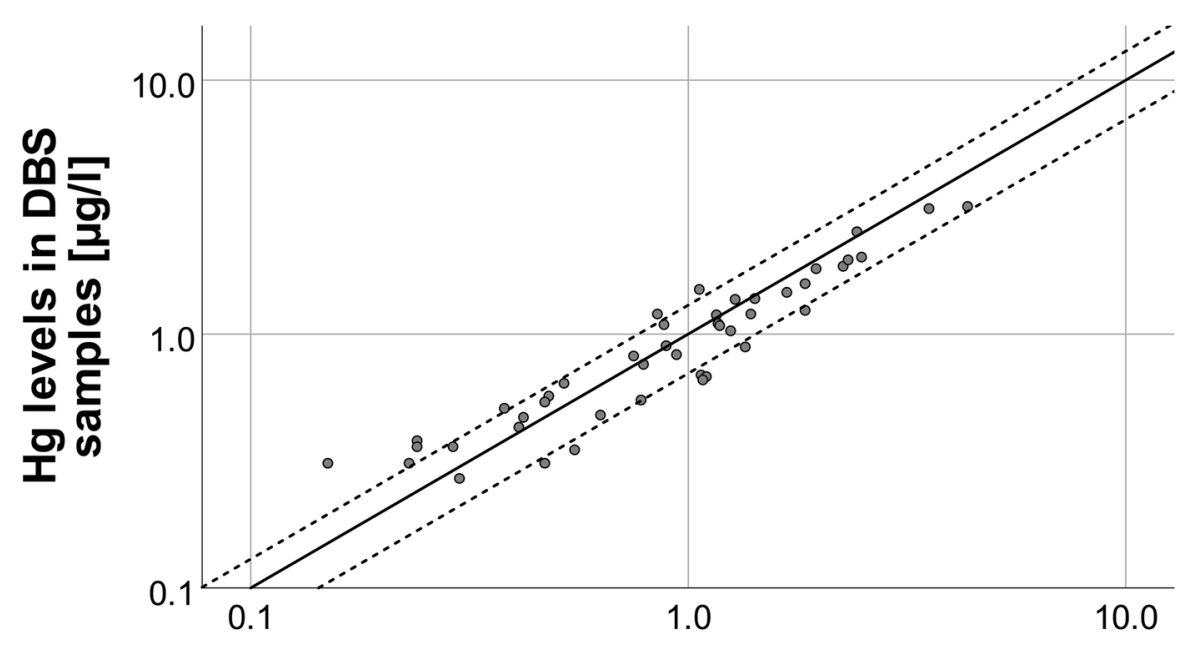

$\mathrm{Hg}$ levels in venous blood samples [ $\mathrm{\mu g} / \mathrm{l}]$ 
Fig. 3 Bland-Altman plot of the absolute differences between $\mathrm{Hg}$ levels in venous blood and DBS samples vs. the mean of $\mathrm{Hg}$ levels in both samples. The mean difference (bias, solid line) was at $-0.09 \mu \mathrm{g} / \mathrm{l}$. The upper and lower statistical limits (0.44 $\mu \mathrm{g} / 1,-0.64 \mu \mathrm{g} / \mathrm{l}$, dashed lines) were calculated by adding 1.96 times the standard deviation of the calculated differences to the mean difference (bias)

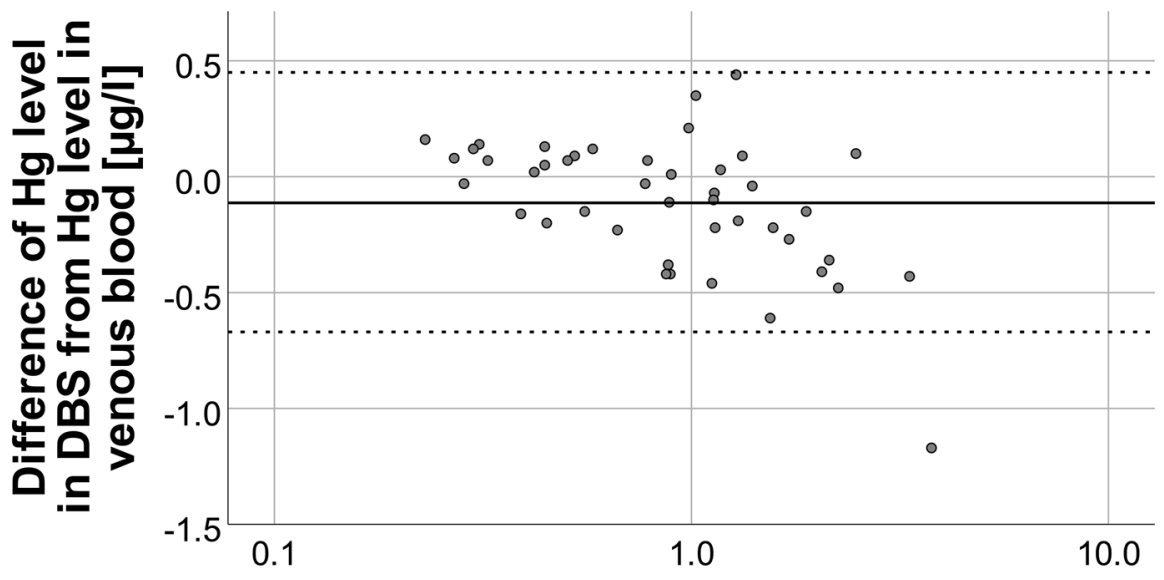

Mean of $\mathrm{Hg}$ level in venous blood and DBS results when the $\mathrm{Hg}$ levels in blood are relatively low. Furthermore, it appears that results from the DBS samples tend to be elevated in samples with venous blood $\mathrm{Hg}$ levels below $0.5 \mu \mathrm{g} / \mathrm{l}$. Above $0.5 \mu \mathrm{g} / \mathrm{l}$, mean recoveries were found to be between 84 and $99 \%$. Because the impact of residual $\mathrm{Hg}$ decreases with increasing $\mathrm{Hg}$ levels in venous blood, lowest scattering of recoveries was found in samples above $\mathrm{Hg}$ levels of $1.5 \mu \mathrm{g} / \mathrm{l}$. The fact that the recoveries for DBS samples with $\mathrm{Hg}$ levels above $1.0 \mu \mathrm{g} / \mathrm{l}$ were below $100 \%$ could be due to a lower blood volume in the punched DBS than the estimated $60 \mu \mathrm{l}$.
Other studies report the influence of hematocrit on the volume of blood in a specific area of DBS card and recommend the weighing of punched spots to adjust for individual hematocrit values (Mei et al., 2001; Nyanza et al., 2019; O’Broin, 1993). However, we deliberately did not weigh the punched DBS spots because the hematocrit levels in humans are in sufficiently narrow physiological ranges for meaningful results (McDade et al., 2007). Finally, no significant difference for $\mathrm{Hg}$ recoveries was found between direct analysis of the DBS cards after drying $(n=17$; median recovery: 103\%) and analysis after storage
Fig. 4 Box plot of the recoveries of $\mathrm{Hg}$ in DBS samples according to different ranges of $\mathrm{Hg}$ levels in venous blood samples. The dotted lines resemble a recovery of $70 \%$ and $130 \%$, respectively. A statistically significant negative trend for the recovery was found with increasing $\mathrm{Hg}$ concentration in venous blood $(p<0.001)$

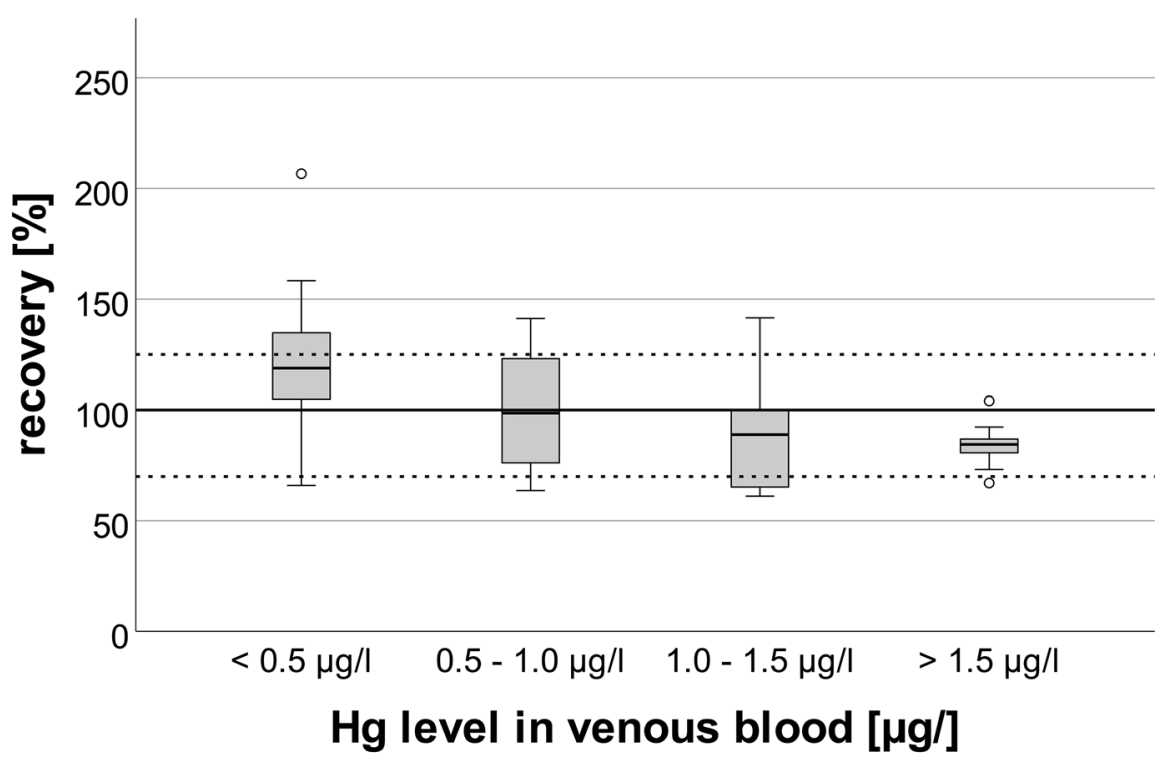


for 1 week ( $\mathrm{n}=27$; median recovery: $88 \%)$. Consequently, the storage of DBS samples in pre-cleaned glass tubes successfully prevented contamination.

Strengths and limitations of the study

The application of DBS sampling in combination with direct $\mathrm{Hg}$ analysis for $\mathrm{Hg}$ biomonitoring is the key strength of our study. Furthermore, our study sheds more light on the stability of $\mathrm{Hg}$ in DBS samples under different storage conditions, especially with regard to storage vessels and temperatures. Our study also emphasizes the importance of the use of fresh blood samples for method development instead of certified reference materials.

A limitation of our study is the fact that the exact blood volume of each DBS was not adjusted for hematocrit levels as suggested in other studies (Basu et al., 2017; Funk et al., 2015; Nyanza et al., 2019). Nevertheless, Funk et al. state that estimated blood volume sufficient for valid results (Funk et al., 2013). Additionally, $\mathrm{Hg}$ levels in capillary blood may be different from venous blood, e.g., due to the dilution by tissue fluid. Furthermore, the LOQ was too low for about $10 \%$ of the DBS samples. This is due to the relatively low blood volume of $60 \mu \mathrm{l}$ on one hand and varying residual $\mathrm{Hg}$ amounts on the DBS cards that interfere greatly with low $\mathrm{Hg}$ amounts from the sampled blood on the other hand. Nonetheless, the LOQ of our method $(0.24 \mu \mathrm{g} / \mathrm{l})$ is, in our opinion, more than sensitive enough to identify people with medium to elevated $\mathrm{Hg}$ levels in blood. However, a better sensitivity may be achieved by using pre-cleaned DBS cards and ICP-MS for analysis as it has been described in other studies (Chaudhuri et al., 2009; Funk et al., 2013, 2015; Nelson et al., 2016; Nyanza et al., 2019). A further limitation of this method is that DBS spots cannot be used for the determination of other trace elements after direct mercury analysis. However, direct mercury analysis of DBS samples is a strength of this study.

\section{Conclusion}

Since DBS samples in studies and human biomonitoring, especially in areas with poor infrastructure, usually cannot be measured immediately after sample collection, the stability of $\mathrm{Hg}$ is an important prerequisite for its applicability. Therefore, we investigated the stability of $\mathrm{Hg}$ in DBS and the optimal storage conditions for DBS samples. To the best of our knowledge, this study is the first to investigate the stability of $\mathrm{Hg}$ in DBS samples in different storage vessels. We also demonstrated that it is advisable to use human blood for method development instead of certified reference materials to study the stability of $\mathrm{Hg}$ in DBS samples during storage. By comparing DBS with venous blood sampled under field conditions, we could show that the Hg levels in DBS samples have comparable precision and good correlation to venous blood samples. In conclusion, DBS sampling is a suitable sampling method in combination with direct $\mathrm{Hg}$ analysis for $\mathrm{Hg}$ biomonitoring. DBS are therefore an alternative to the common venous blood sampling. As DBS sampling only requires $60 \mu \mathrm{l}$ capillary blood per spot, compared to several milliliters for venous blood sampling, this method may be particularly suitable for the $\mathrm{Hg}$ biomonitoring of infants and newborns. The second advantage is that DBS samples do not require a cooling chain and could therefore be used in remote areas, such as ASGM areas, to screen the $\mathrm{Hg}$ levels of miners. In summary, microsampling-assisted $\mathrm{Hg}$ biomonitoring may be a useful addition to assess and reduce $\mathrm{Hg}$ exposure in line with the Minamata convention. However, more research is required to further improve the sensitivity and sample stability of DBS.

Author contribution Ann-Kathrin Schweizer: sampling, sample analysis, data analysis, visualization, preparation of the original draft, writing-review \& editing. Michael Kabesch: supervision, conceptualization, writing-review \& editing. Caroline Quartucci: sampling, supervision, writingreview \& editing. Stephan Bose-O'Reilly: supervision, conceptualization, methodology, data analysis, writing-review \& editing. Stefan Rakete: conceptualization, methodology, funding acquisition, data analysis, writing-review \& editing, preparation of the final manuscript. All authors have given approval to the final version of the manuscript.

Funding Open Access funding enabled and organized by Projekt DEAL. This study was funded by the Friedrich-Baur foundation (Reg.-Nr. 27/18).

Availability of data and materials Individual anonymized $\mathrm{Hg}$ levels of the participants can be found in the supplementary material. Further anonymized data may be made available upon reasonable request. 


\section{Declarations}

Ethics approval The study was carried out in accordance with the Code of Ethics of the Declaration of Helsinki for experiments involving human subjects and reviewed and approved by the ethics committee of the Ludwig Maximilians University of Munich (20-091).

Consent to participate Informed consent was obtained from all individual participants included in the study.

Consent for publication The participants signed an informed consent for publishing aggregated or anonymized data.

Conflict of interest The authors declare no competing interests.

Open Access This article is licensed under a Creative Commons Attribution 4.0 International License, which permits use, sharing, adaptation, distribution and reproduction in any medium or format, as long as you give appropriate credit to the original author(s) and the source, provide a link to the Creative Commons licence, and indicate if changes were made. The images or other third party material in this article are included in the article's Creative Commons licence, unless indicated otherwise in a credit line to the material. If material is not included in the article's Creative Commons licence and your intended use is not permitted by statutory regulation or exceeds the permitted use, you will need to obtain permission directly from the copyright holder. To view a copy of this licence, visit http://creativecommons.org/licenses/by/4.0/.

\section{References}

Afrifa, J., Opoku, Y.K., Gyamerah, E.O., Ashiagbor, G., \& Sorkpor, R.D. (2019). The clinical importance of the mercury problem in artisanal small-scale gold mining. Frontiers in Public Health, 7, 131-131. https://doi.org/10. 3389/fpubh.2019.00131

Basu, N., Eng, J.W.L., Perkins, M., Santa-Rios, A., Martincevic, G., Carlson, K., et al. (2017). Development and application of a novel method to characterize methylmercury exposure in newborns using dried blood spots. Environmental Research, 159, 276-282. https://doi.org/10.1016/j.envres. 2017.08.021

Basu, N., Horvat, M., Evers, D.C., Zastenskaya, I., Weihe, P., \& Tempowski, J. (2018). A state-of-the-science review of mercury biomarkers in human populations worldwide between 2000 and 2018. Environmental Health Perspectives, 126(10), 106001. https://doi.org/10.1289/ehp3904

Bernhoft, R.A. (2012). Mercury toxicity and treatment: A review of the literature. Journal of Environmental and Public Health, 2012, 460508-460508. https://doi.org/10. $1155 / 2012 / 460508$

Bose-O'Reilly, S., Bernaudat, L., Siebert, U., Roider, G., Nowak, D., \& Drasch, G. (2017). Signs and symptoms of mercury-exposed gold miners. International Journal of
Occupational Medicine and Environmental Health, 30(2), 249-269. https://doi.org/10.13075/ijomeh.1896.00715

Bose-O'Reilly, S., McCarty, K.M., Steckling, N., \& Lettmeier, B. (2010). Mercury exposure and children's health. Current Problems in Pediatric and Adolescent Health Care, 40(8), 186-215. https://doi.org/10.1016/j.cppeds.2010.07.002

Chaudhuri, S.N., Butala, S.J., Ball, R.W., \& Braniff, C. T. (2009). Pilot study for utilization of dried blood spots for screening of lead, mercury and cadmium in newborns. Journal of Exposure Science \& Environmental Epidemiology, 19(3), 298-316. https://doi.org/10.1038/jes. 2008.19

Funk, W.E., McGee, J.K., Olshan, A.F., \& Ghio, A.J. (2013). Quantification of arsenic, lead, mercury and cadmium in newborn dried blood spots. Biomarkers, 18(2), 174-177. https://doi.org/10.3109/1354750x.2012.750379

Funk, W.E., Pleil, J.D., Sauter, D.J., McDade, T., \& Holl, J.L. (2015). Use of dried blood spots for estimating children's exposures to heavy metals in epidemiological research. Journal of Environmental \& Analytical Toxicology, S7(2).

Genchi, G., Sinicropi, M.S., Carocci, A., Lauria, G., \& Catalano, A. (2017). Mercury exposure and heart diseases. International Journal of Environmental Research and Public Health, 14(1). https://doi.org/10. 3390/ijerph14010074

Lehmann, S., Delaby, C., Vialaret, J., Ducos, J., \& Hirtz, C. (2013). Current and future use of "dried blood spot" analyses in clinical chemistry. Clinical Chemistry and Laboratory Medicine, 51(10), 1897-1909. https://doi.org/10. 1515/cclm-2013-0228

McDade, T.W., Williams, S., \& Snodgrass, J.J. (2007). What a drop can do: Dried blood spots as a minimally invasive method for integrating biomarkers into population-based research. Demography, 44(4), 899-925. https://doi.org/10. 1353/dem.2007.0038

Mei, J.V., Alexander, J.R., Adam, B.W., \& Hannon, W.H. (2001). Use of filter paper for the collection and analysis of human whole blood specimens. Journal of Nutrition, 131(5), 1631s-1636s. https://doi.org/10.1093/jn/131.5. $1631 \mathrm{~S}$

Nelson, J.W., Edhlund, B.L., Johnson, J., Rosebush, C.E., Holmquist, Z.S., Swan, S.H., et al. (2016). Assessing a new method for measuring fetal exposure to mercury: Newborn bloodspots. International Journal of Environmental Research and Public Health, 13(7), 692. https:// doi.org/10.3390/ijerph13070692

Nyanza, E.C., Bernier, F.P., Manyama, M., Hatfield, J., Martin, J.W., \& Dewey, D. (2019). Maternal exposure to arsenic and mercury in small-scale gold mining areas of Northern Tanzania. Environmental Research, 173, 432-442. https:// doi.org/10.1016/j.envres.2019.03.031

O'Broin, S. (1993). Influence of hematocrit on quantitative analysis of "blood spots" on filter paper. Clinical Chemistry, 39(6), 1354-1355.

Ostler, M.W., Porter, J.H., \& Buxton, O.M. (2014). Dried blood spot collection of health biomarkers to maximize participation in population studies. Journal of Visualized Experiments, (83), e50973. https://doi.org/10.3791/50973

Perkins, M., \& Basu, N. (2018). Dried blood spots for estimating mercury exposure in birds. Environmental Pollution, 
236, 236-246. https://doi.org/10.1016/j.envpol.2018.01. 036

Santa-Rios, A., Barst, B.D., \& Basu, N. (2020). Mercury speciation in whole blood and dried blood spots from capillary and venous sources. Analytical Chemistry, 92(5), 3605-3612. https://doi.org/10.1021/acs.analchem.9b04407

Sundseth, K., Pacyna, J.M., Pacyna, E.G., Pirrone, N., \& Thorne, R.J. (2017). Global sources and pathways of mercury in the context of human health. International Journal of Environmental Research and Public Health, 14(1), 105. https://doi. org/10.3390/ijerph14010105
United Nations Environment Programme UNEP (2013). Mercury: Time to act

United Nations Environment Programme UNEP (2019). Global Mercury Assessment 2019. Sources, Emissions, Releases and Environmental Transport.

Publisher's Note Springer Nature remains neutral with regard to jurisdictional claims in published maps and institutional affiliations. 